\title{
Inhalt
}

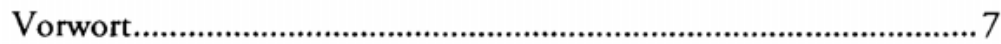

Nahost und Arabische Halbinsel

Waghalsige Flucht vor dem Checkpoint..........................................21

Beten und Bangen hinter dem Erdwall...........................................24

Und der Jordan öffnet sich doch! ................................................... 41

Zwiespalt und Resignation im unheiligen Land ..............................53

Erstart in der Politik der Steine ..................................................59

Die Grenzen, die heimlich wandern ..............................................70

Drusische Hochzeiten im Minenfeld ................................................75

Die Wüste verschlingt den roten Stern ............................................91

Der endgültige Sieg des Halbmonds................................................ 119

Balkan

Der multi-ethnische Traum trotzt den Granaten ......................... 128

Rückkehr in eine geschundene Stadt .........................................150

Ein Leben in der ethnisch sauberen Einöde................................... 157

Am Horizont der Höllenstadt glänzt ein Silberstreifen ................... 164

Der Held, der auf der „falschen “ Seite kämpfte ............................. 179

Auf den Spuren von Alexander dem Grenzenlosen......................... 184

\section{Indischer Subkontinent}

Die hässliche Narbe der verfeindeten Brüder................................ 197

Im Tal der zitternden Erde kämpfen die

„Urenkel Alexanders“ ums Überleben

\section{Lateinamerika}

Das Friedenslabor in der Höhle des Löwen

Dreiländer-Dschungel:

Ureinwohner im Fluss der Moderne.

Index. 
Der Autor:

Dr. Carsten Wieland ist Redakteur bei der Deutschen Presse-Agentur (dpa) und Politikberater. Als Korrespondent hat er mehrere Jahre unter anderem aus dem Nahen Osten, den USA und Kolumbien berichtet. Wieland hat Geschichte, Politik, Philosophie und Internationale Beziebungen an der Humboldt-Universität Berlin, an der Duke University in North Carolina (USA) und an der Jawaharlal Nehru Universität in Neu-Delhi (Indien) studiert. Zudem lernte er in der Universität Damaskus Arabisch und war Fellow an der Georgetown University in Washington. Während des Bosnien-Kriegs berichtete Wieland 1994 als freier Journalist aus Sarajevo. Er promovierte über einen Vergleich zur muslimischen Nationsbildung und ethnischen Konflikten in Bosnien und Indien/ Pakistan. 